\section{Marker-assisted screening of breeding populations of an apomictic grass Cenchrus ciliaris L. segregating for the mode of reproduction}

\author{
Suresh Kumar ${ }^{1,2^{*}}$, Sheena Saxena ${ }^{1}$ and Madan G. Gupta ${ }^{1}$
}

\begin{abstract}
Cenchrus ciliaris $L$. is an apomictic forage grass grown in pastures and rangelands of the semi-arid tropics. It reproduces predominantly through apomixis; rarely, obligate sexual plants have also been reported. Absence of sexual reproduction limits the possibility of genetic improvement through hybridization. This study reports on hybridization of an obligate sexual, self-incompatible buffelgrass with pollen from apomictic plants towards development of an $F_{2}$ population segregating for mode of reproduction and use of sequence characterized amplified region (SCAR) markers for screening the population. The segregation ratio of 3:1 (facultative: apomictic) was observed in the $F_{1}$ generation, whereas it was 1:2:1 (apomictic: facultative: sexual) in the $F_{2}$ generation. A number of obligate sexual $F_{2}$ progenies with desirable agronomic traits were obtained. The SCAR markers were able to screen out apomictic plants from sexual ones, but failed to discriminate between facultative and sexual. Marker-assisted screening could be useful for introgression of desirable trait(s) in the apomictic genotype through hybridization.
\end{abstract}

Key words: SCAR, apomixis, molecular marker, sexual reproduction.

\section{INTRODUCTION}

Buffelgrass (Cenchrus ciliaris L.) is one of the most important perennial forage grasses grown throughout the tropical and subtropical regions of the world. It is an apomictic, polyploid grass suited to pastures and rangelands of Australia, South Africa, and India (Bhat et al. 2001). It is drought tolerant and well adapted to arid and semi-arid areas. A serious disease in buffelgrass is leaf blight caused by Magnaporte grisea, which reduces forage quality and yield (Rodriguez et al. 1999). A natural source of resistance to this disease is known (Diaz-Franco and Mendez-Rodríguez 2005), but lack of sexual reproduction restricts genetic improvement of this species through hybridization. Apomixis not only makes genetic improvement of the species difficult and time consuming, but restricts it to selection of elite lines from the natural variants (Kumar and Bhat 2012). On the other hand, apomixis provides a means of clonal propagation through seeds because the progenies produced through apomixis are genetically identical to the female parent. Apomictic Cenchrus species reproduce by apospory, characterized by apomeiosis and parthenogenesis. Recently, the ASGR-BABY BOOM-like (PSASGR-BBML) gene from Pennisetum squamulatum (L.) R.Br. has been reported to express in egg cells before fertilization and induce parthenogenesis, as well as produce haploid offspring in transgenic sexual pearl millet (Conner et al. 2015).
Crop Breeding and Applied Biotechnology 17: 10-17, 2017 Brazilian Society of Plant Breeding. Printed in Brazil http://dx.doi.org/10.1590/198470332017v17n1a2 
Induction of parthenogenesis by PSASGR-BBML can be of value for inducing parthenogenesis to synthesize apomixis in crop plants and may be applied to haploid induction to rapidly obtain homozygous lines for breeding. However, success in transfer of apomixis to a crop species has not yet been reported, mainly because the gene(s) for the components of apomixis has (have) not yet been identified (Spillane et al. 2004, Kandemir and Saygili 2015).

Though apomixis may be introgressed into the crop plant through conventional breeding, the process is slow and laborious and requires embryological/progeny analysis of huge breeding populations for selection of apomictic genotypes after each round of backcrossing (Albertini et al. 2001). Moreover, there are certain breeding constraints in this, including the availability of desired parental lines and efficient techniques for screening the segregating populations. In most of the species, apomixis shows dominance over the sexual mode; hence, the occurrence of an obligate sexual plant is rare and, over time, apomictic individuals outnumber sexual ones. Nevertheless, obligate sexual plants of buffelgrass have been identified (Bray 1978, Kumar et al. 2010b). A natural variant of an Indian accession of buffelgrass was reported to be short in stature, protogynous, and obligate sexual in nature (Kumar et al. 2013). The first genetic linkage map for the sexual mode of reproduction in C. ciliaris was reported based on recombining and closely linked AFLP markers by Yadav et al. (2012). Lack of sexual reproduction limits genetic improvement of this species through hybridization (Kumar and Bhat 2012). The only successful method of varietal development in this species has been selection of elite lines from the natural variants. With the identification of an obligate sexual plant of buffelgrass (Kumar et al. 2010b), it was possible to conduct hybridization experiments not only for basic studies (genetic analysis for the apomixis trait) but also for applied research (creation of genetic diversity and selection of elite genotypes) towards variety development.

To discriminate between apomictic and sexual modes of reproduction, embryological analysis of developing ovules using paraffin and resin embedded sectioning have been successful, but they are very time-consuming and cumbersome methods. The benzyl benzoate- $4 \frac{1}{2}$ technique was first used by Herr (1971) for this purpose; later on, several modifications of the original method were adopted to study ovule development in angiosperms (Farence and Smith 1975, Shealy 1980). Subsequently, Young et al. (1979) used a pistil-clearing technique as an alternative to the time-consuming and cumbersome embedding and sectioning methods. The pistil-clearing technique requires less (one-tenth) time compared to that of the sectioning method, yet it involves nine subsequent changes through ethanol and methyl salicylate series. Moreover, it requires fixing of florets at an appropriate developmental stage after initiation of flowering. Since then, the most commonly used and reliable methods for investigating the apomictic mode of reproduction in plants have been either embryological analysis of the mother plant (Mazzucato et al. 1996) or its progeny analysis (Barcaccia et al. 1997). Since the pistil- clearing technique is still time consuming, labor intensive, and reliant on the developmental stage (flowering) of the plant, it may prove not to be an efficient technique for screening larger segregating populations.

Marker-assisted screening (MAS) is an efficient technique to minimize the time and labor required in a breeding program. Some of the requirements for MAS include (i) simple genetic inheritance of the trait under selection and (ii) availability of markers tightly linked with the trait (Albertini et al. 2001). The data available on the apomictic mode of reproduction indicate that apomixis is under simple genetic control not only in C. ciliaris (Goel et al. 2003, Dwivedi et al. 2007, Yadav et al. 2012) but also in Poa pratensis (Barcaccia et al. 1998), Panicum maximum (Savidan 1983), Pennisetum squamulatum (Gustine et al. 1997, Ozias-Akins et al. 1998, Roche et al. 1999), Brachiaria decumbens (Pessino et al. 1997), Paspalum notatum (Martinez et al. 2003), and Tripsacum dactyloides (Leblanc et al. 1995). Molecular analyses have revealed that only a few dominant genes are required for genetic transmission of apomixis (Barcaccia et al. 1998, Goel et al. 2003, Yadav et al. 2012). Moreover, the role of transposable elements and their epigenetic controls (Wang et al. 2016) are also being investigated in regulation of the genes associated with apomixis (our unpublished data). The molecular markers linked with sexual and apomictic modes of reproduction (Kumar et al. 2010c, Kumar and Saxena 2016) would be very useful for screening of the segregating population, mapping of genes responsible for the mode of reproduction, and their characterization using a reverse genetics approach (Kumar 2014).

The present study was undertaken to create genetic diversity in apomictic buffelgrass through hybridization and to demonstrate the utility of the SCAR markers (Kumar et al. 2010c, Kumar and Saxena 2016) in breeding procedures. The SCAR marker-assisted screening of the segregating population would be very useful for genetic/molecular analyses of apomixis and marker-assisted breeding of buffelgrass. 


\section{MATERIAL AND METHODS}

\section{Plant material}

A tetraploid obligate sexual C. ciliaris (IGFRI-CcSx -08/1) plant (Kumar et al. 2013) was grown in a greenhouse in isolation, as well as cross pollinated with an apomictic $C$. ciliaris plant (IG-693108). Seeds were collected from the crosspollinated obligate sexual plant and the obligate apomictic plant. Progenies of both the plants were raised and analyzed using RAPD and SCAR markers. A facultative $F_{1}$ progeny of the sexual plant was selfed by bagging an individual panicle before emergence of the stigma. A total of $287 \mathrm{~F}_{2}$ progenies were raised from the seeds collected from the selfed $F_{1}$ and screened using four apomixis-specific SCAR markers (Kumar and Saxena 2016) and one sexual SCAR marker (Kumar et al. 2010c).

\section{Genomic DNA isolation}

Genomic DNA was isolated from leaf tissues of the parents and $F_{1}$ and $F_{2}$ progenies following a simplified protocol reported elsewhere (Kumar et al. 2010a). Young leaf tissues were ground in $200 \mu \mathrm{L}$ of AP1 Lysis buffer (QIAGEN GmbH). The ground sample was incubated at $65^{\circ} \mathrm{C}$ for $15 \mathrm{~min}$, and then $65 \mu \mathrm{L}$ of P3 Neutralization buffer (QIAGEN GmbH) was added, followed by incubation on ice for $5 \mathrm{~min}$. The content was centrifuged for $5 \mathrm{~min}$ at $9000 \mathrm{~g}$, and a 0.6 volume of isopropanol was mixed with the supernatant. The mixture was centrifuged and the DNA pellet was washed with $70 \%$ ethanol, air-dried, and finally dissolved in $30 \mu \mathrm{L}$ of sterilized double-distilled water. The quality of the genomic DNA was checked by agarose gel $(0.8 \% \mathrm{w} / \mathrm{v})$ electrophoresis.

\section{Progeny analysis}

Progenies of the sexual and the apomictic plants were subjected to comparative evaluation for morphological variation (Figure 1), and analyzed for genetic variability using PCR-based RAPD markers with reactive decamer primers (Unpublished data). Morphological diversity among individuals was assessed based on the data collected (with respect to plant height, leaf length and width, panicle size, and fresh biomass production) in triplicate at the flowering stage over three years. PCR amplification for RAPD analysis was performed in a $20 \mu \mathrm{L}$ reaction volume containing 100 ng genomic DNA, $400 \mathrm{mM}$ of each dNTP, 30 pmol primer, $2.5 \mathrm{mM} \mathrm{MgCl}$, $1 \times$ Taq buffer, and $3 \mathrm{U}$ Taq DNA polymerase on a PTC- $100^{\circ}$ Peltier thermal cycler (MJ Research). PCR conditions were $94^{\circ} \mathrm{C}$ for $5 \mathrm{~min}$, followed by 40 cycles of $94{ }^{\circ} \mathrm{C}$ for $60 \mathrm{~s}, 37^{\circ} \mathrm{C}$ for $60 \mathrm{~s}, 72^{\circ} \mathrm{C}$ for $2 \mathrm{~min}$, and a final extension at $72{ }^{\circ} \mathrm{C}$ for $10 \mathrm{~min}$. The amplification products were visualized on $1.5 \%$ agarose gel.

\section{Marker-assisted screening (MAS) of progenies}

The mode of reproduction in the progenies of the sexual and the apomictic plants was first determined using a sexual SCAR marker (CcSex-260: Forward 5'-GAGCAGGGGTTAGAGGTAA-3', Reverse 5'-ACATTCAGCCTACGGAGTG-3') (Kumar et al. 2010c) and four apomixis-specific SCAR markers (Apo-C270, Apo-C470, Apo-C730, Apo-C930) (Kumar and Saxena 2016). The apomixis-specific markers can detect the obligate apomictic mode of reproduction in Cenchrus spp. The sexual SCAR marker detects sexuality in Cenchrus ciliaris; however, it
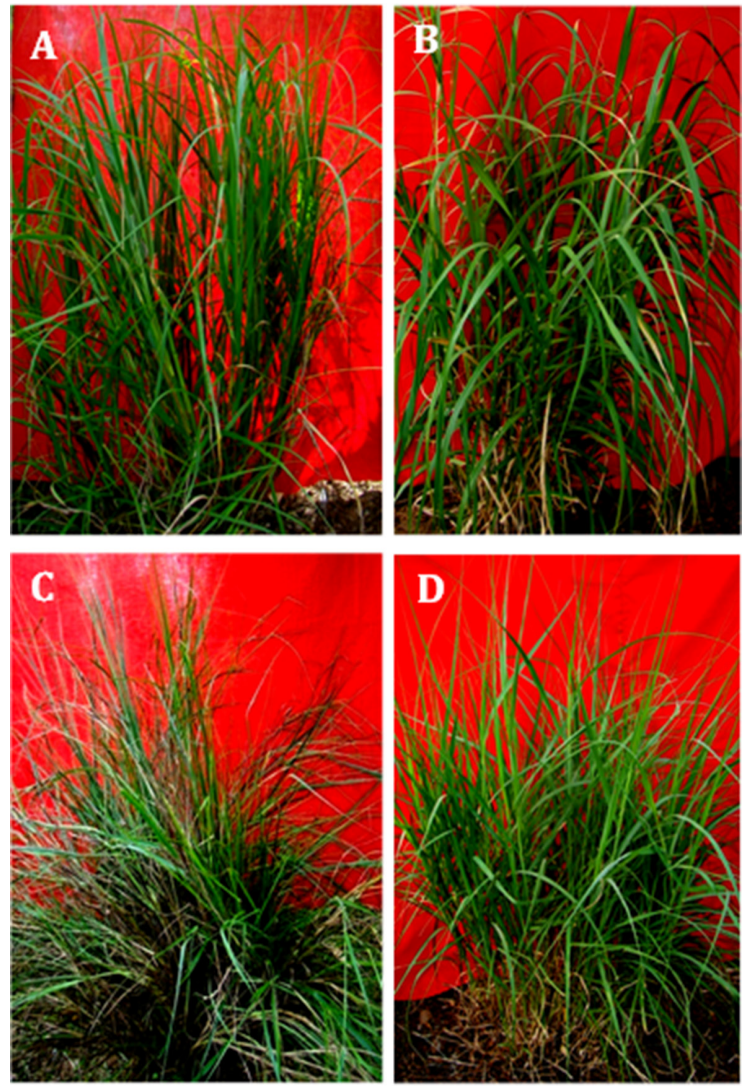

Figure 1. Morphological diversity among $F_{1}$ hybrids of the sexual C. ciliaris plant. A - Apomictic $F_{1}$ hybrid with longer, broader leaves and better regrowth potential, $B$ - Apomictic $F_{1}$ hybrid showing heterosis for leaf size, $C$ - Facultative $F_{1}$ hybrid with distinct morphological features, $D$ - Another facultative $F_{1}$ hybrid morphologically similar to the male parent. 
does not differentiate between sexual and facultative modes of reproduction. Screening of $287 \mathrm{~F}_{2}$ progenies of $C$. ciliaris for mode of reproduction was performed using the sexual and apomixis-specific SCAR markers. PCR-based MAS was carried out using $100 \mathrm{ng}$ genomic DNA, $100 \mathrm{mM}$ of each dNTP, $10 \mathrm{pmol}$ of each of the primers, $2 \mathrm{mM} \mathrm{MgCl}, 1 \mathrm{x} \mathrm{Taq}$ buffer, and $3 \cup$ Taq DNA polymerase. PCR conditions were $94^{\circ} \mathrm{C}$ for $5 \mathrm{~min}$, followed by 38 cycles of DNA amplification (94 ${ }^{\circ} \mathrm{C}$ for $60 \mathrm{~s}, 60^{\circ} \mathrm{C}$ for $60 \mathrm{~s}$, and $72{ }^{\circ} \mathrm{C}$ for $30 \mathrm{~s}$ ) and final incubation at $72{ }^{\circ} \mathrm{C}$ for $5 \mathrm{~min}$. The PCR products were visualized by $1.4 \%$ agarose gel electrophoresis.

\section{Embryo sac analysis}

To confirm the mode of reproduction detected by the molecular markers and to validate fidelity of the MAS, embryo sac analysis was performed as described elsewhere (Kumar et al. 2015). All of the $F_{1}$ hybrids and selected $F_{2}$ individuals were subjected to the pistil-clearing technique (Young et al. 1979) by analyzing 25 cleared pistils from each plant. Based on the presence or absence of antipodal cells, the embryo sac was categorized as sexual or apomictic. The presence of both sexual and apomictic embryo sacs on the same inflorescence categorized the plant as facultative.

\section{Statistical analysis}

Statistical analysis of the data collected from a minimum of three replications was performed by analysis of variance. Duncan's multiple range test (DMRT) was used to compare the means. The $\chi^{2}$ test was used to determine goodness of fit (at $P<0.05$ ) between the observed and expected number of genotypes for the segregation ratio of either 3:1 or 1:2:1.

\section{RESULTS AND DISCUSSION}

When the obligate sexual C. ciliaris plant (IGFRI-CCSx -08/1) was grown in isolation, normal flowering was observed, but no seed setting was found. On growing the sexual plant along with apomictic plants in a greenhouse, seed setting on the sexual plant was observed. Thus, cross-pollination of the sexual plant was necessary for seed setting. The selfincompatible nature of the sexual plant bearing viable pollens was confirmed over three years of experimentation. This report on the self-incompatibility of the sexual parent is unique and has not previously been reported in buffelgrass. The reported self-incompatibility of the sexual plant would be a desirable feature so as to minimize the efforts required for cross-hybridization (hand-pollination).

\section{Marker-assisted screening of segregating populations}

SCAR markers known to be linked with sexual and apomictic modes of reproduction (Kumar et al. 2010c, Kumar and Saxena 2016) were utilized for screening of segregating populations developed by crossing the obligate sexual plant with pollen from the tetraploid obligate apomictic $C$. ciliaris plant (IG-693108). The sexual mode of reproduction and cross-fertilization of the tetraploid obligate sexual plant was confirmed by $F_{1}$ progeny analyses wherein morphologically diverse (Figure 1), facultative, and apomictic progenies were observed. SCAR marker-assisted screening of $F_{1}$ hybrids resulted in identification of 10 hybrids (out of $34 \mathrm{~F}_{1}$ progenies) as apomictic. Screening with the sexual SCAR marker, followed by embryo sac analysis, confirmed that the remaining 24 hybrids were facultative. Facultative sexual progenies are supposed to be heterozygous, and they were found to be self-compatible since selfing of the facultative $F_{1}$ progeny produced sexual, apomictic, and facultative $F_{2}$ individuals. The $F_{1}$ progenies were found to be either apomictic or facultative, but no sexual progeny was observed. This may be due to the tetraploid nature of the species, and this observation is in agreement with earlier reports in buffelgrass (Dwivedi et al. 2007, Yadav et al. 2012) and Brachiaria (Pessino et al. 1997). Selfing of a facultative $F_{1}$ plant by bagging, followed by collection of seeds to raise the $F_{2}$ generation, resulted in a segregating population of 287 individuals. Screening of the $F_{2}$ individuals using the sexual and apomixis-specific SCAR markers resulted in identification of 71 apomictic individuals, showing amplification with the apomixis-specific SCAR markers but no amplification with the sexual SCAR marker (Figure 2A and B).

Use of more than one SCAR markers (four apomixis-specific and one sexual SCAR marker) rendered sufficient fidelity to MAS for screening out apomictic individuals. In fact, the absence of the sexual SCAR marker itself indicated the apomictic mode of reproduction in the plant, but amplification with apomixis-specific SCAR markers confirmed the result. The sexual SCAR marker was detected in the remaining $216 \mathrm{~F}_{2}$ individuals (Figure 2B), with no band for any of the apomixis-specific SCAR markers (Figure 2A). However, further examination of these individuals by the pistil-clearing 


\section{S Kumar et al.}

technique resulted in identification of 158 individuals as facultative. The test of segregation ratio for the mode of reproduction using the $c^{2}$ test indicated a 1:3 ratio (apomictic: facultative) in the $F_{1}$ generation, whereas a 1:2:1 (apomictic: facultative: sexual) ratio was observed in the $F_{2}$ generation (Table 1). The observed distortion in the $F_{1}$ segregation ratio (3:1 instead of 1:1) might be due to the polyploid nature of the species. In $\mathrm{F}_{2}$, a dosage effect can be assumed, with sexual being aaaa, facultative being Aaaa, and apomictic being AAaa. After selfing a facultative (Aaaa), we expect a sexual: facultative: apomictic segregation ratio of $1: 2: 1$ (71:155:58).

Molecular markers provide a reliable and sensitive technique for molecular plant breeding (Albertini et al. 2001, Santana et al. 2014). Their use is particularly important when the selectable phenotype is manifested late in the plant life cycle (Albertini et al. 2001). Since the apomixisspecific SCAR markers were identified from conserved apomixis-specific loci in four apomictic Cenchrus species (Kumar and Saxena 2016), they were able to unequivocally distinguish apomictic genotypes from sexual/facultative. Therefore, these SCAR markers can be used for MAS of segregating populations, including those from inter-specific hybridization carried out for introgression of desirable

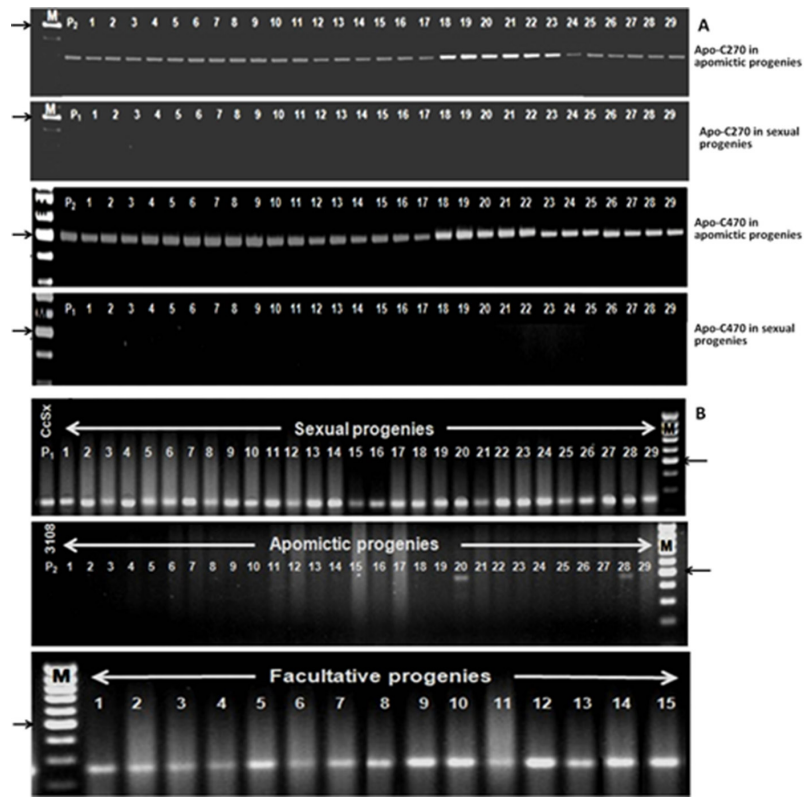

Figure 2. Marker-assisted screening of $F$ progenies using $A$ apomixis-specific SCAR markers (Apo-C270, Apo-C470) and B - sexual SCAR marker (CCSx-260). $P_{1}=$ mother sexual plant, $P_{2}=$ apomictic parent, $\mathrm{CcSx}=$ sexual parent, $3108=$ apomictic parent. Arrows (-->) indicate 500 bp band in the 100 bp DNA size marker. trait(s) from other Cenchrus species.

\section{Embryological analysis to detect mode of reproduction}

Based on the presence of antipodal cells, the embryo was categorized as sexual, whereas the absence of antipodal cells led to an apomictic classification. To validate the fidelity of MAS, we performed embryological analysis of the $F_{1}$ and $\mathrm{F}_{2}$ progenies and looked for the presence or absence of antipodal cells in the cleared pistil under a DIC microscope. Only the individual that was positive for the sexual SCAR marker, bearing an eight-nucleate embryo sac, was categorized as sexual, whereas those bearing both sexual and apomictic embryos were categorized as facultative. Since embryological and progeny analyses are laborious and time consuming, there are limitations to their application in screening of breeding populations. Using PCR-based (SCAR) markers linked with the mode of reproduction, we could overcome some of these limitations.

\section{Diversity among the progenies}

Whereas the mother sexual plant was short in stature, with poor growth and development, its $F_{1}$ progenies showed considerable morphological variation with respect to plant height (56 to $127 \mathrm{~cm})$, leaf length $(11$ to $30.8 \mathrm{~cm})$, width (4.3 to $15.2 \mathrm{~mm}$ ), panicle structure and size $(5.8$ to $9.8 \mathrm{~cm}$ ), and fresh biomass production (756 to $3458 \mathrm{~g}$ per plant) at flowering. RAPD analysis of randomly selected $F_{1}$ hybrids of the sexual plant showed significant variation in their DNA profiles, whereas the randomly selected progenies of an apomictic plant showed similar DNA profiles (Figure 3). $F_{2}$ progenies of the sexual plant also showed considerable morphological diversity with respect to plant height (26 to

Table 1. Trait segregation (apomictic, sexual, and facultative) in $F_{1}$ and $F_{2}$ progenies of Cenchrus ciliaris

\begin{tabular}{lccccc}
\hline Progeny & Observed ratio & Expected ratio & Segregation ratio & $\chi^{2}$ value & $\begin{array}{c}\text { P-value } \\
(P=0.05)\end{array}$ \\
\hline$F_{1}$ & $24(F): 10(A)$ & $25(F): 9(A)$ & $3: 1$ & $0.151^{*}$ & 3.84 \\
$F_{2}$ & $71(A): 158(F): 58(S)$ & $72(A): 143(F): 72(S)$ & $1: 2: 1$ & $4.309^{*}$ & 5.99 \\
\hline
\end{tabular}

$A=$ apomictic, $F=$ facultative, $S=$ sexual

* Non-significant at $\mathrm{P}=0.05$ 


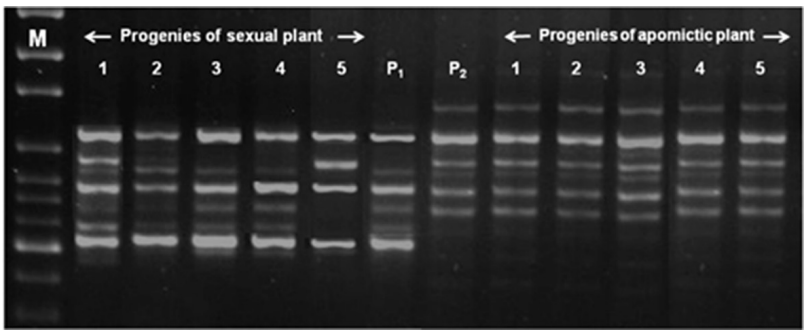

Figure 3. RAPD profile of five (1-5) randomly selected progenies of the sexual $\left(P_{1}\right)$ and an apomictic $\left(P_{2}\right) C$. ciliaris plant. $M=100$ bp DNA size marker.

$132 \mathrm{~cm}$ ), leaf morphology, panicle characteristics, mode of reproduction (apomictic/sexual/facultative), regrowth potential, and biomass production (356 to $3656 \mathrm{~g}$ per plant) at the $50 \%$ flowering stage. The morphological variations observed among the progenies of the sexual plant confirmed its utility in creating the genetic diversity required for genetic improvement and varietal development in this apomictic species. The observed morphological diversity among the apomictic $F_{1}$ hybrids (Figure $1 \mathrm{~A}$ and B) demonstrated that apomixis can be successfully utilized to fix heterosis in a hybrid.

\section{Selection of elite genotypes}

The mother sexual plant showed meager growth and development over the years (Figure 4A) compared to the normally occurring apomictic buffelgrass (Figure 4B). While most of the progenies surpassed the mother sexual plant for several agronomic traits, a number of sexual (Figure 4C) and apomictic (Figure 4D) $F_{2}$ progenies with desirable agronomic features could also be identified. Diversity among the $\mathrm{F}_{2}$ progenies resulted in selection of 17 genotypes on the basis of their plant height, leaf structure, growth potential, and biomass production for station trials toward varietal development. Most of the selected progenies were on par with the apomictic parent for many of the agronomic traits, while exceeding it for one or two features, particularly for biomass production and regrowth potential.

Although there are reports of hybridization in buffelgrass (Dwivedi et al. 2007, Yadav et al. 2012), the main objective of those studies was to develop an $F_{2}$ mapping population for genetic analysis of the apomixis trait and identification of molecular markers linked to it. No morphological assessment of parents and progenies for agronomic traits has been reported before. While the mother sexual plant (IGFRI-CcSx -08/1) was the only obligate sexual genotype (showing meager growth and development), a number (8) of obligate sexual $F_{2}$ progenies with desirable agronomic traits (Figure 4C) was able to be obtained through hybridization. Several apomictic $F_{2}$ progenies with desirable attributes (leaf structure, regrowth potential, and biomass production) led to the selection of 9 promising genotypes for station trials toward varietal development (Figure 4D).

These findings show that hybridization can be used for creating genetic diversity in apomictic species and fixing heterosis through introgression of apomixis. Whenever a desirable trait has to be introgressed into an apomictic genetic background, an apomictic parent may be used as a male parent, and sexual progenies with the desirable trait(s) will need to be selected in each backcross generation. Once the recurrent parental genotype is recovered, selection will need to be directed to select apomictic individuals with the introgressed trait. Therefore, the molecular markers must have maximum fidelity in selection of apomictic and sexual genotypes. The sexual and apomixis-specific SCAR markers 


\section{S Kumar et al.}

used in the present study were successful in MAS of segregating populations with sufficient fidelity. Although the sexual SCAR marker could not discriminate between sexual and facultative individuals, the four apomixis-specific SCAR markers unambiguously identified the apomictic genotypes. Most of the earlier reports on molecular markers linked with the apomictic or sexual mode of reproduction (Albertini et al. 2001, Yadav et al. 2012) did not describe their status in facultative genotypes. Although a facultative-specific marker may not be so important in a breeding program, it may be useful for genetic/molecular analyses of apomixis. Therefore, it would be desirable to identify a marker linked with the facultative mode of reproduction to minimize dependence on embryological/progeny analyses.

\section{REFERENCES}

Albertini E, Barcaccia G, Porceddu A, Sorbolini S and Falcinelli M (2001) Mode of reproduction is detected by Parth1 and Sex1 SCAR markers in a wide range of facultative apomictic Kentucky bluegrass varieties. Molecular Breeding 7: 293-300.

Barcaccia G, Mazzucato A, Albertini E, Zethof J, Pezzotti M, Gerats A and Falcinelli M (1998) Inheritance of parthenogenesis in Poa pratensis L.: auxin test and AFLP linkage analyses support monogenic control. Theoretical and Applied Genetics 97: 74-82.

Barcaccia G, Mazzucato A, Belardinelli A, Pezzotti M, Lucretti S and Falcinelli M (1997) Inheritance of parental genomes in progenies of Poa pratensis $\mathrm{L}$. from sexual and apomictic genotypes as assessed by RAPD markers and flow cytometry. Theoretical and Applied Genetics 95: 516-524.

Bhat V, Dalton SJ, Kumar S, Bhat BV, Gupta MG and Morris P (2001) Particle-inflow gun-mediated genetic transformation of buffelgrass (Cenchrus ciliaris L.): optimizing biological and physical parameters. Journal of Applied Genetics 42: 405-412.

Bray RA (1978) Evidence for facultative apomixis in Cenchrus ciliaris. Euphytica 27: 801-804.

Conner JA, Mookkan M, Huo H, Chae K and Ozias-Akins P (2015) A parthenogenesis gene of apomict origin elicits embryo formation from unfertilized eggs in a sexual plant. Proceedings of National Academy of Science of USA 112: 11205-11210.

Diaz-Franco A and Mendez-Rodriguez A (2005) Leaf blight [Pyricularia grisea (Cooke) Sacc] in buffelgrass (Cenchrus ciliaris L.) meadows and reaction of genotypes in North Tamaulipas, Mexico. Revista Mexicana de Fitopatologia 23: 232-237.

Dwivedi KK, Bhat SR, Bhat V, Baht BV and Gupta MG (2007) Identification of a SCAR marker linked to apomixis in buffelgrass (Cenchrus ciliaris L.). Plant Science 172: 788-795.

Farence DR and Smith BB (1975) Effect of chemical pretreatments on Ludwigia alternifolia L. ovules prior to immersion in Herr's clearing fluid. Proceedings of Pennsylvania Academy of Science 29: 89-91.

Goel S, Chen Z, Conner JA, Akiyama Y, Hanna WW and Ozias-Akins P (2003) Physical evidence that a single hemizygous chromosomal region is sufficient to confer aposporous embryo sac formation in Pennisetum squamulatum and Cenchrus ciliaris. Genetics 163: 1069-1082.

Gustine DL, Sherwood RT and Huff DR (1997) Apospory-linked molecular markers in buffelgrass. Crop Science 37: 947-951.
Herr JMJr (1971) A new clearing squash technique for the study of ovule development in Angiosperms. In Radford AE, Dickson WC, Massey JR and Bell CR (eds) Vascular plant systematic. Harer and Row, New York, p. 230-235.

Kandemir N and Saygili I (2015) Apomixis: new horizons in plant breeding. Turkish Journal of Agriculture and Forestry 39: 1-8.

Kumar S (2014) RNAi (RNA interference) vectors for functional genomics study in plants. National Academy of Science Letters 37: 289-294.

Kumar S and Bhat V (2012) High-frequency direct plant regeneration via multiple shoot induction in the apomictic forage grass Cenchrus ciliaris L. In Vitro Cellular \& Developmental Biology-Plant 48: 241248.

Kumar S and Saxena S (2016) Sequence characterized amplified regions linked with apomictic mode of reproduction in four different apomictic Cenchrus species. Molecular Plant Breeding 7: 1-14.

Kumar S, Arul L and Talwar D (2010a) Generation of marker-free Bt transgenic indica rice and evaluation of its yellow stem borer resistance. Journal of Applied Genetics 51: 243-257.

Kumar S, Chandra A, Gupta MG and Shukla GP (2010b) Molecular and embryological analyses of rare sexual plant in buffelgrass (Cenchrus ciliaris L.). Range Management \& Agroforestry 31: 36-40.

Kumar S, Chandra A, Gupta MG and Shukla GP (2010c) SCAR marker linked to sexuality in Cenchrus ciliaris L. Range Management \& Agroforestry 31: 149-150.

Kumar S, Chandra A, Gupta MG and Shukla GP (2013) IGFRI-CcSx-08/1 (IC0590889; INGR11062), an Anjan grass (Cenchrus ciliaris L.) germplasm with a rare obligate sexual plant. Indian Journal of Plant Genetic Resources 26: 99-100.

Kumar S, Sahu N and Singh A (2015) High-frequency in vitro plant regeneration via callus induction in a rare sexual plant of Cenchrus ciliaris L. In Vitro Cellular \& Developmental Biology-Plant 51: 28-34.

Leblanc O, Grimanelli D, de Leon DG and Savidan Y (1995) Detection of the apomictic mode of reproduction in maize-Tripsacum hybrids using maize RFLP markers. Theoretical and Applied Genetics 90: 1198-1203.

Martinez EJ, Hopp HE, Stein J, Ortiz JPA and Quarin CL (2003) Genetic characterization of apospory in tetraploid Paspalum notatum based on the identification of linked molecular markers. Molecular Breeding 12: 319-327.

Mazzucato A, Falcinelli M and den Nijs APM (1996) Estimation of 
parthenogenesis frequency in Kentucky bluegrass with auxin induced parthenocarpic seeds. Crop Science 36: 9-16.

Ozias-Akins P, Roche D and Hanna WW (1998) Tight clustering and hemizygosity of apomixis-linked molecular markers in Pennisetum squamulatum implies genetic control of apospory by a divergent locus which may have no allelic form in sexual genotypes. Proceedings of National Academy of Science of USA 95: 5127-5132.

Pessino SC, Ortiz J, Leblanc O, do Valle CB and Hayward MD (1997) Identification of a maize linkage group related to apomixis in Brachiaria. Theoretical and Applied Genetics 94: 439-444.

Roche D, Peisheng C, Zhenbang C, Hanna WW, Gustine DL, Sherwood RT and Ozias-Akins P (1999) An apospory-specific genomic region is conserved between buffelgrass (Cenchrus ciliaris L.) and Pennisetum squamulatum Fresen. Plant Journal 19: 203-208.

Rodriguez O, Gonzalez-Dominguez J, Krausz JP, Odvody GN, Wilson JP, Hanna WW and Lew M (1999) First report and epidemics of buffelgrass blight caused by Pyricularia grisea in South Texas. Plant Diseases 83: 398.

Santana FA, Silva MF, Guimarães JKF, Silva MF, Pereira WD, Piovesan WD and Barros WG (2014) Marker-assisted selection strategies for developing resistant soybean plants to cyst nematode. Crop Breeding and Applied Biotechnology 14: 180-186.
Savidan Y (1983) Genetics and utilization of apomixis for the improvement of guinea grass (Panicum maximum Jacq.). In Smith JA and Hays VW (eds) Proceedings of international grassland congress. Lexington, KY, p. 182-184.

Shealy HEJr (1980) Treatment of dense ovule wall with monoethanolamine used in conjunction with clearing technique. Association of Southeastern Biologists Bulletin 27: 62.

Spillane C, Curtis MD and Grossniklaus U (2004) Apomixis technology development-virgin births in farmers' fields? Nature Biotechnology 22: 687-691.

Wang X, Li Q, Yuan W, Cao Z, Qi B, Kumar S, Li Y and Qian W (2016). The cytosolic Fe-S cluster assembly component MET18 is required for the full enzymatic activity of ROS1 in active DNA demethylation. Scientific Reports 6: 26443 doi: 10.1038/srep26443.

Yadav CB, Anuj, Kumar S, Gupta MG and Bhat V (2012) Genetic linkage maps of the chromosomal regions associated with apomictic and sexual modes of reproduction in Cenchrus ciliaris. Molecular Breeding 30: 239-250.

Young BA, Sherwood RT and Bashaw EC (1979) Cleared pistil and thick sectioning techniques for detecting aposporous apomixis in grasses. Canadian Journal of Botany 57: 1668-1672. 